Research Article

\title{
Numerical Simulation for Mechanical Behavior of Asphalt Pavement with Graded Aggregate Base
}

\author{
Dongliang He $\mathbb{I D}^{1}$ and Yanhui Cheng $\mathbb{D}^{2}$ \\ ${ }^{1}$ School of Civil Engineering, Hunan City University, Yiyang, Hunan 413000, China \\ ${ }^{2}$ College of City Management, Hunan City University, Yiyang, Hunan 413000, China \\ Correspondence should be addressed to Dongliang He; hedongliang14@126.com
}

Received 29 December 2017; Accepted 8 February 2018; Published 21 March 2018

Academic Editor: Hang Lin

Copyright (C) 2018 Dongliang He and Yanhui Cheng. This is an open access article distributed under the Creative Commons Attribution License, which permits unrestricted use, distribution, and reproduction in any medium, provided the original work is properly cited.

\begin{abstract}
The performance of asphalt pavement is determined by the combination of its material properties, road structure, and loading configurations. A DEM numerical simulation study was conducted to determine stress distribution and deformation behavior of asphalt pavement with graded aggregate base under standard traffic loading. Stress contour and displacement contour were presented via a self-made program. Compressive stress concentrated area located in both sides of wheel, while tensile stress concentrated area appeared in lower part of the asphalt layer. The traffic loading transferred downward by graded aggregate base and to both sides at the same time, and has a trend to expand gradually with increasing depth within graded aggregate base. Therefore, stress was well distributed in the subgrade soil layer with a great action scope, and the value decreased obviously because of the stress dispersion of graded aggregate base. Vertical displacement was the main displacement of the asphalt layer, and on the both sides of traffic loading, displacement was downward and inclined slightly to the central of loading. Vertical and horizontal deformations included in both graded aggregate base layers, and displacement extended to both sides gradually with increasing depth corresponding to stress-distribution trends. Vertical displacement was dominated in the subgrade soil layer which was relatively small.
\end{abstract}

\section{Introduction}

In the built and rebuilt highways, approximately $90 \%$ of pavements in China are asphalt-surfaced pavements, and much of their subgrade was semirigid base. However, as the subgrade is used extensively, there are some problems that appear progressively, and subjected to repeated traffic loading, premature failures, and lower maintenance over the life cycle of the pavements [1-4]. The common distress modes in pavements are likely fatigue cracking and rutting which decrease the service life of pavement. This is a phenomenon that pavement design and maintenance engineers stripping off asphalt in flexible pavement have had to contend with for years [5-8]. Fatigue cracking and rutting were triggered by leading infiltration of rainwater into subgrade base, which has been found responsible for premature failures $[8,9]$.

A series of investigation on mechanical properties of graded aggregate base material (referring to assembly of granular materials for construction of highway base layers) was performed alone [10-15] to meet the engineering needs, both under motonic and cyclic loading conditions. However, the behavior of pavements is complex and depends on many factors such as the axle/wheel loading configurations, the materials used, the thickness of the layers, and the environmental conditions [16]. Mechanistic-empirical design methods use greatly simplified models [17] and is now moving to more mechanistic-based approaches [10, 18]. Stress level within each layer of a pavement structure is determined by magnitude of the load, individual and combined layer thickness, and layer material properties [16, 19]. And long-term stability of pavements can only be achieved with a properly designed and constructed system that consists of all pavement structural components and sufficient understanding of their interaction $[6,20]$. Therefore, it is imperative to investigate pavement stability by considering its structure. This paper presents a discrete element method (DEM) [21-23] numerical 
TABle 1: Particle size distributions of the graded aggregate.

\begin{tabular}{lcc}
\hline Particle size $(\mathrm{mm})$ & Test content $(\%)$ & Numerical content $(\%)$ \\
\hline 37.5 & 100 & 100.0 \\
31.5 & 90 & 90.0 \\
26.5 & 82.6 & 83.4 \\
19 & 69.9 & 70.7 \\
16 & 64.2 & 65.4 \\
13.2 & 58.3 & 59.4 \\
9.5 & 49.5 & 50.6 \\
4.75 & 35 & 35.4 \\
2.36 & 24.3 & 24.4 \\
1.18 & 16.9 & 16.8 \\
\hline
\end{tabular}

simulation study to determine stress distribution and deformation behavior of asphalt pavement with graded aggregate base under standard traffic loading. And stress and displacement contours were presented to describe them visually via a self-made program, which offers trends of stress and displacement quantitatively. Subsequently, comparison of deformation performance and stress distribution was made to verify the interaction of layers, especially graded aggregate base. The method and conclusion provide a useful tool and guidance to pavement structure design for engineering.

\section{Modelling Procedure}

Over the years, DEM is broadly applied to simulate the mechanical performance of unboned granular materials [24-27]. And particle flow code (PFC) has been successfully employed to study the mechanical behavior of granular materials, especially for railway ballast [28-30]. The numerical software PFC2D is used to study the graded aggregate, comprising particles, and influence on pavement deformation. However, it must be noted that calculation efficiency significantly decreases with increase of particles, and this is also the disadvantage for almost all particle flow models. Furthermore, DEM concerns about micromechanics behavior with a small scope of study object. Therefore, a simplified model is employed to obtain reliable results and efficient calculation both, as follows.

2.1. Simplification. Because of the aforementioned reasons, the object must be carefully planned and conducted to be successful. Firstly, good particle control is necessary to provide efficient calculation. Generally, a highway has a width up to tens of meters, but owing to symmetry of it, the scope of simulation can be reduced in half. Meanwhile, soil of the subgrade layer is not the focus of the current research, so it is default to deem that particle size used in simulation is greater than the minimum particle size of graded aggregate base material. However, particle size for the soil should be in a reasonable radius to prevent graded aggregate base material from entering the soil. On the other hand, the present study mainly focuses on the influence of graded aggregate base on pavement performance; therefore, the selected gradation of granular materials is used as GanDing highway base materials with the maximum particle size of $37.5 \mathrm{~mm}$. Particle size distributions of the graded aggregates are shown

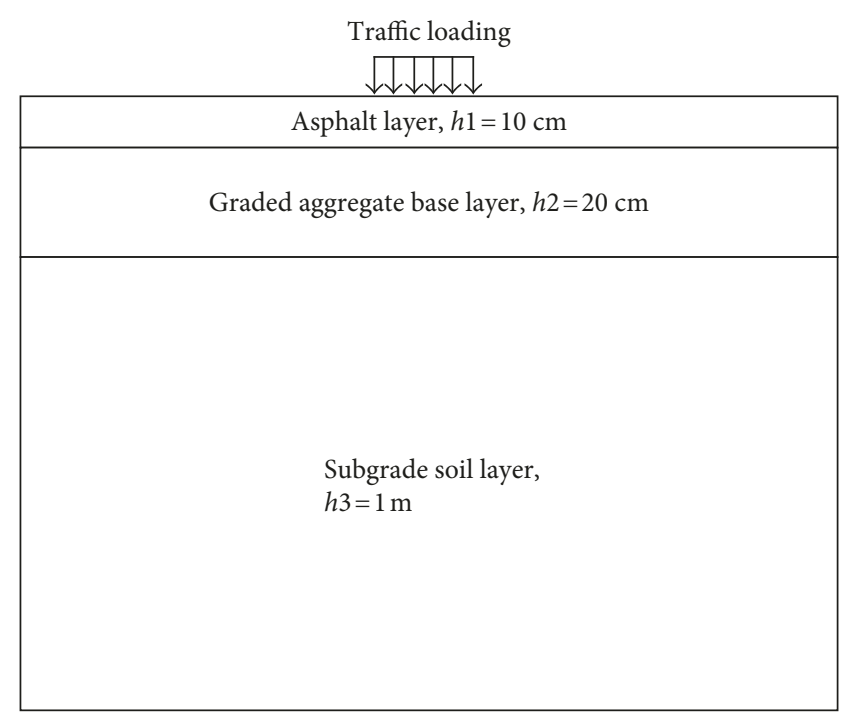

FIgURE 1: Highway structure.

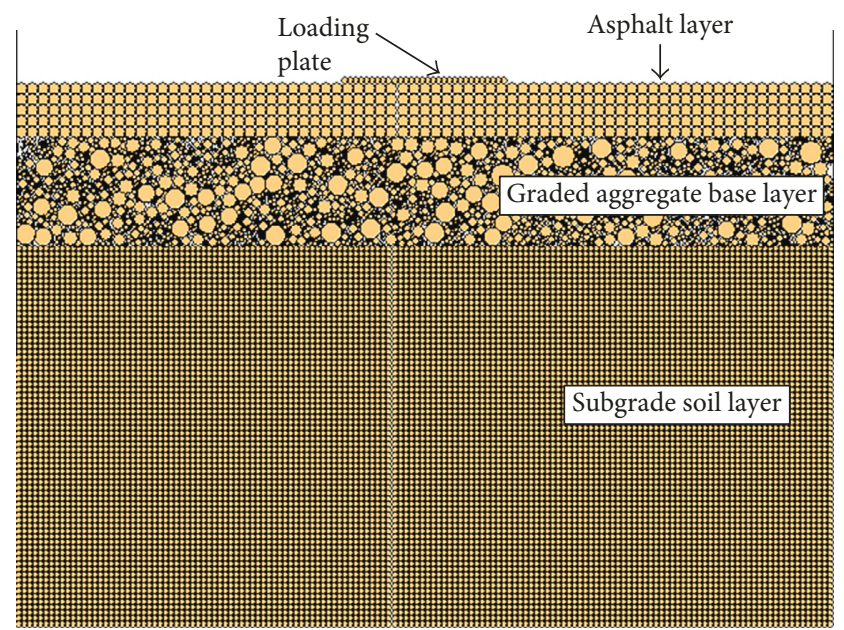

Figure 2: Numerical model.

in Table 1. As illustrated in Table 1, the gradation of the particles in the numerical simulation met that in reality, and the maximum error was less than $0.8 \%$.

2.2. Pavement Structure and Modelling. Through the analysis, the partial pavements (Figures 1 and 2) were selected to investigate the influence of granular material on pavement performance under traffic loading. As shown in Figure 1, the partial covers a half of single line, including a wheel width of $0.3 \mathrm{~m}$ and a width of $0.6 \mathrm{~m}$ on both sides of it. Figure 1 illustrates the highway structure for modelling, which could be categorized into four parts: (1) Asphalt layer: flexible pavements with a thickness of $10 \mathrm{~cm}$. (2) Graded aggregate base layer: composed of specific gradation of granular material, with a thickness of $20 \mathrm{~cm}$. It mainly bears the loads from the asphalt layer and disperses them, so the stress concentration is reduced, which could decrease vertical deformation of subgrade soil. At the same time, it can drain 
TABle 2: Properties for each part.

\begin{tabular}{lccc}
\hline Parts & Generation & Properties & Contact models \\
\hline Asphalt layer & Regular arrangement & Elastomer & Contact and parallel bonds \\
Graded aggregate base layer & Random permutation & Unbound granular & Parallel bonds \\
Subgrade soil layer & Regular arrangement & Elastomer & Contact and parallel bonds \\
Loading plate & Regular arrangement & Elastomer & Clump \\
\hline
\end{tabular}
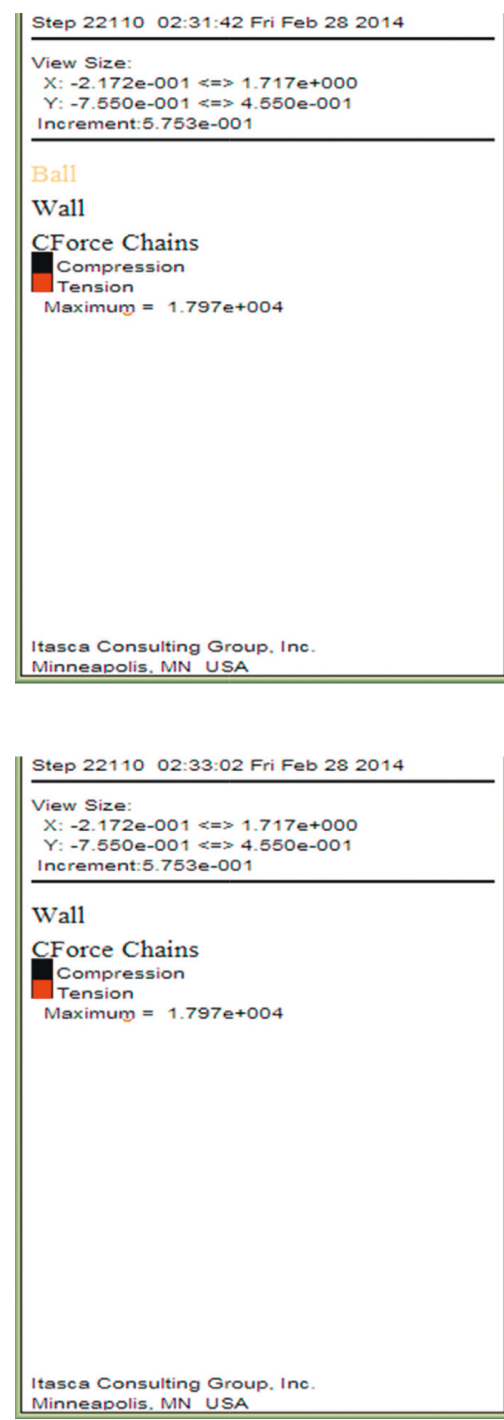

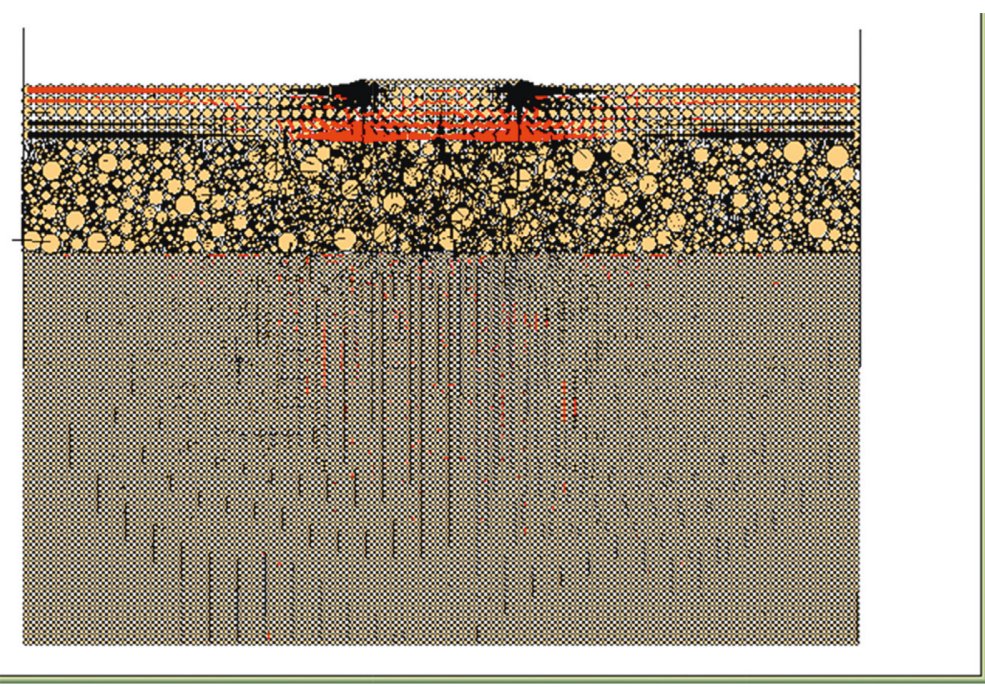

(a)

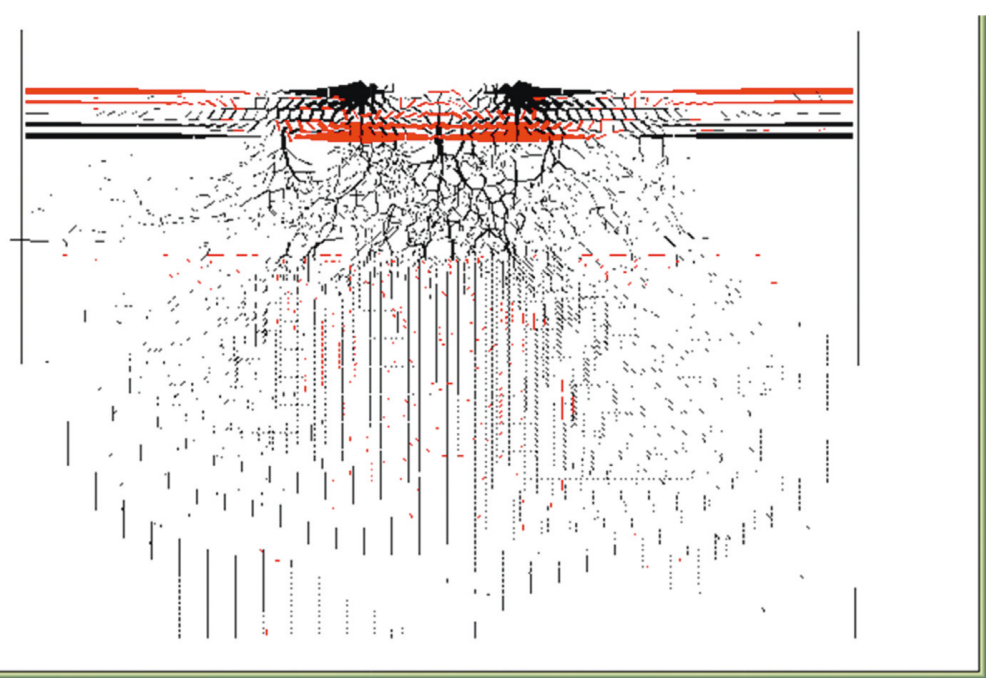

(b)

FIGURE 3: Stress distribution of the model (black and red denote pressure and tension, resp.).

freely and prevent moisture damage. (3) Subgrade soil layer: an integral part of highway. In general, the subgrade soil layer is regarded as a homogeneous semi-infinite plane and infinite in thickness direction. Consolidation deformation under gravity is the mainly vertical deformation, and traffic loading has limited impact scope as stress uniformly distributed in subgrade soil after the stress dispersion of graded aggregate base. Therefore, $1 \mathrm{~m}$ was selected as the thickness of it. (4) Level of traffic loading: according to the Chinese Standard JTG D50-2006 [31], standard axle load equals
$100 \mathrm{kN}$, as such the stress, $50 \mathrm{kN}$, uniformly distributed on pavement with a width of $30 \mathrm{~cm}$ for one side.

The process of modelling and the input parameters are listed in Table 2. (1) Asphalt layer: asphalt is typical of the viscoelastoplastic material, with prominent viscous properties at high temperature and elastic property at low temperature. Thus, the asphalt layer is stratiform elastomer, without considering the viscous properties, in the simulation. The assembly of balls is arranged regularly and tightly within a specified region, and contact and parallel bonds are used to meet the assumption. 

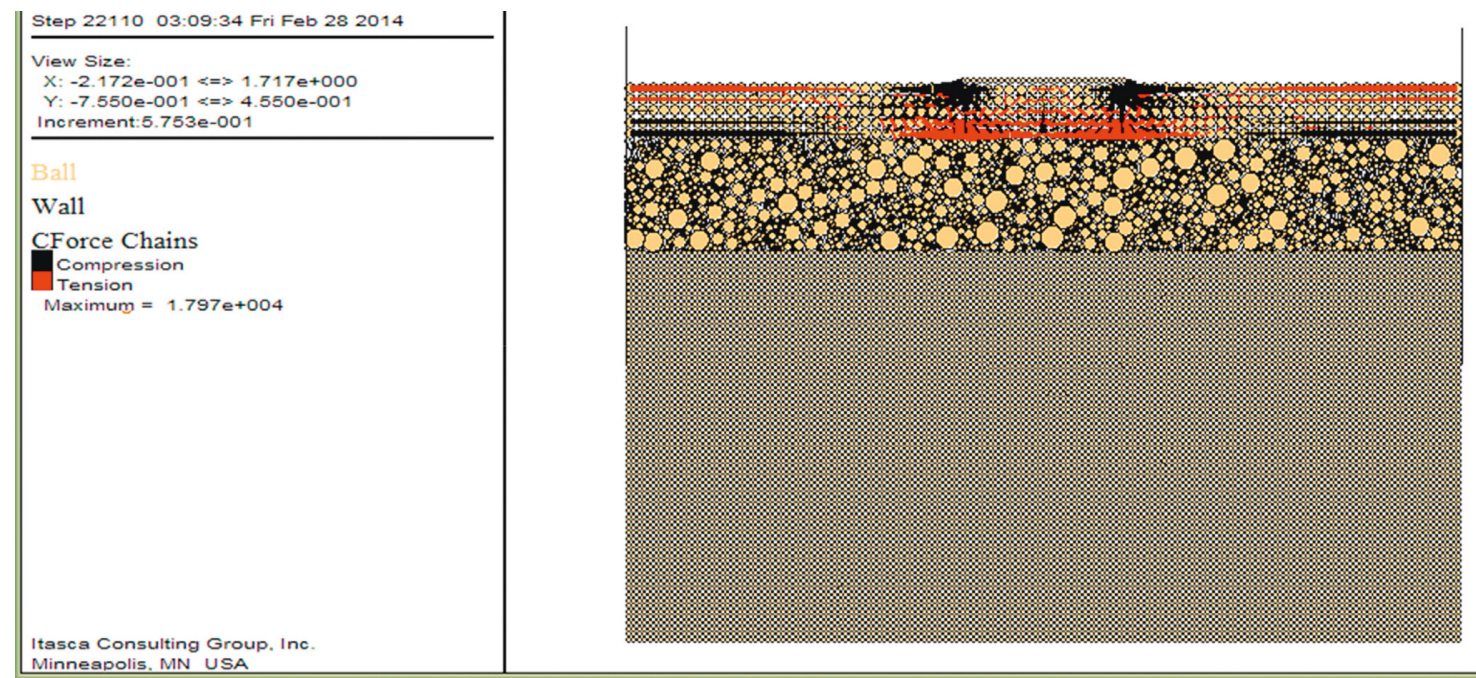

FIGURE 4: Stress distribution of the asphalt layer (black and red denote pressure and tension, resp.).
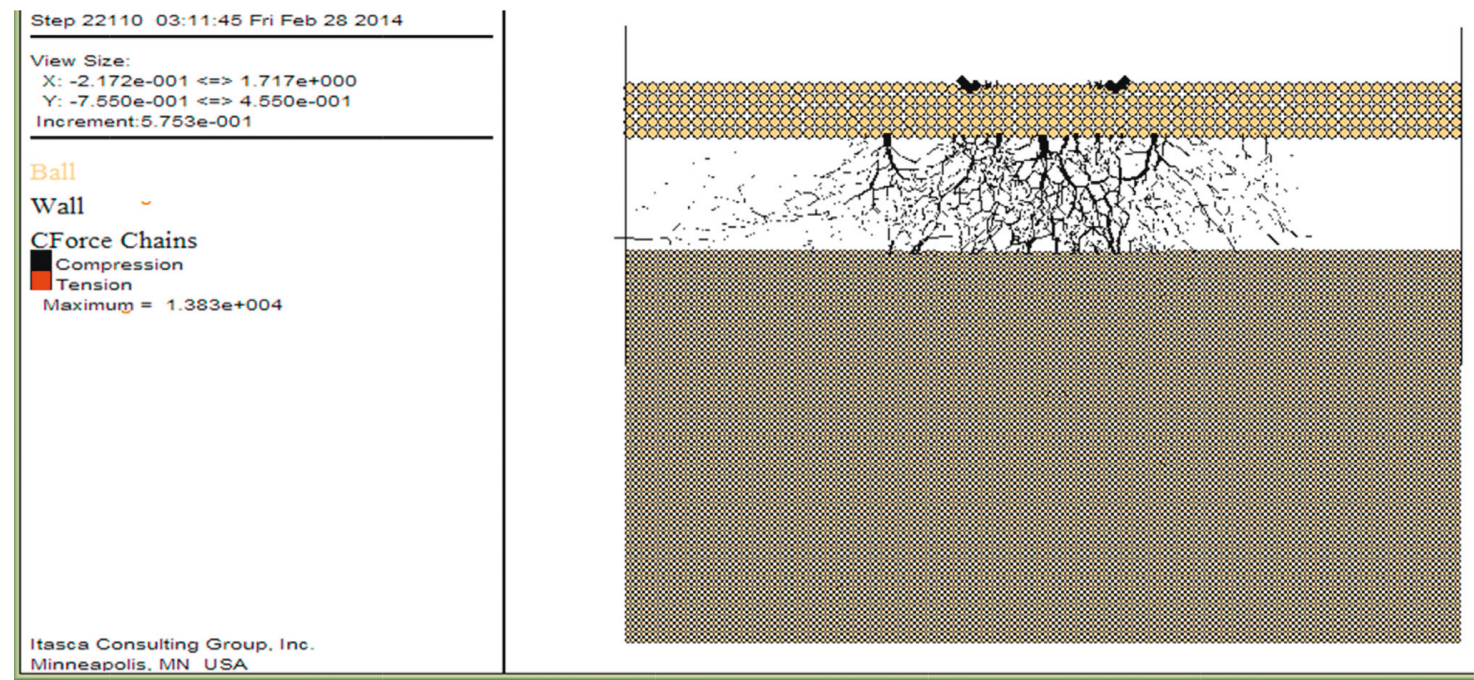

Figure 5: Stress distribution of graded aggregate base layer (black and red denote pressure and tension, resp.).
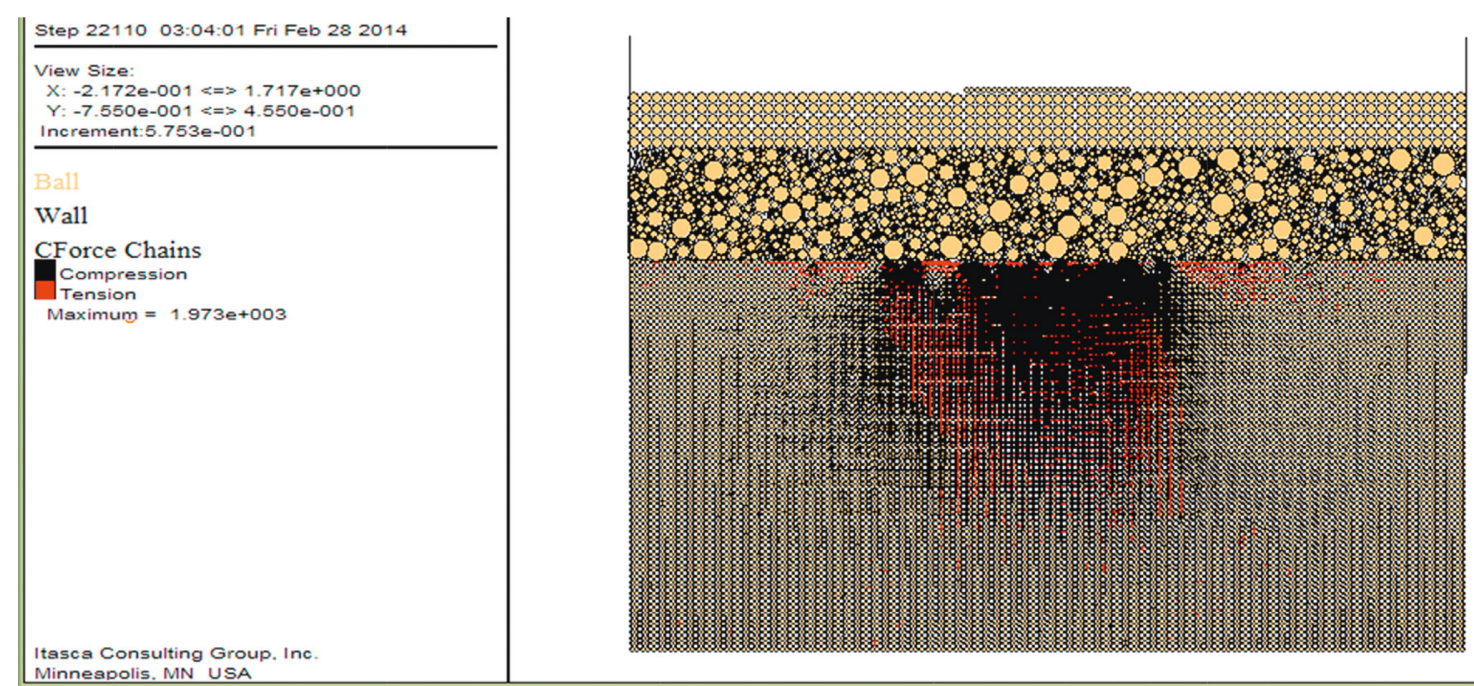

FIgURE 6: Stress distribution of subgrade soil layer (black and red denote pressure and tension, resp.). 


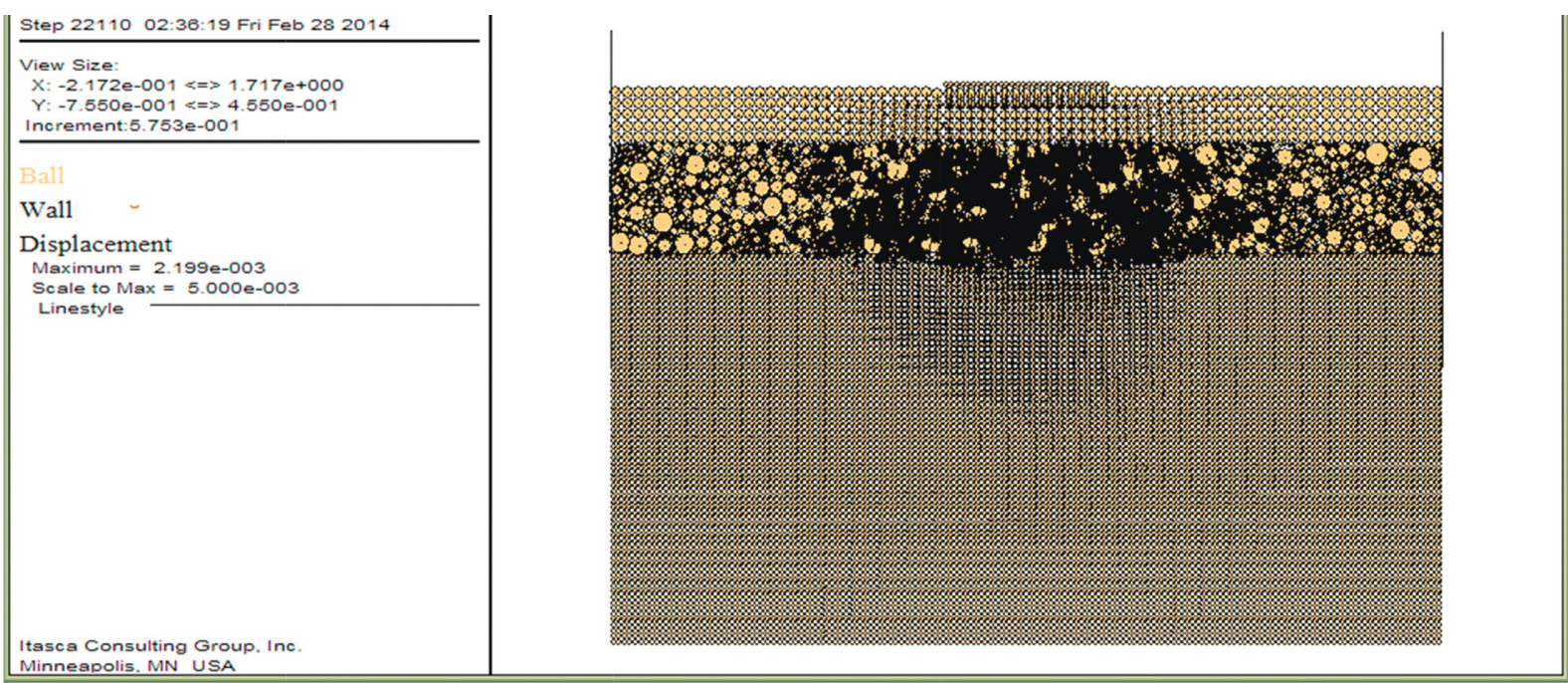

(a)

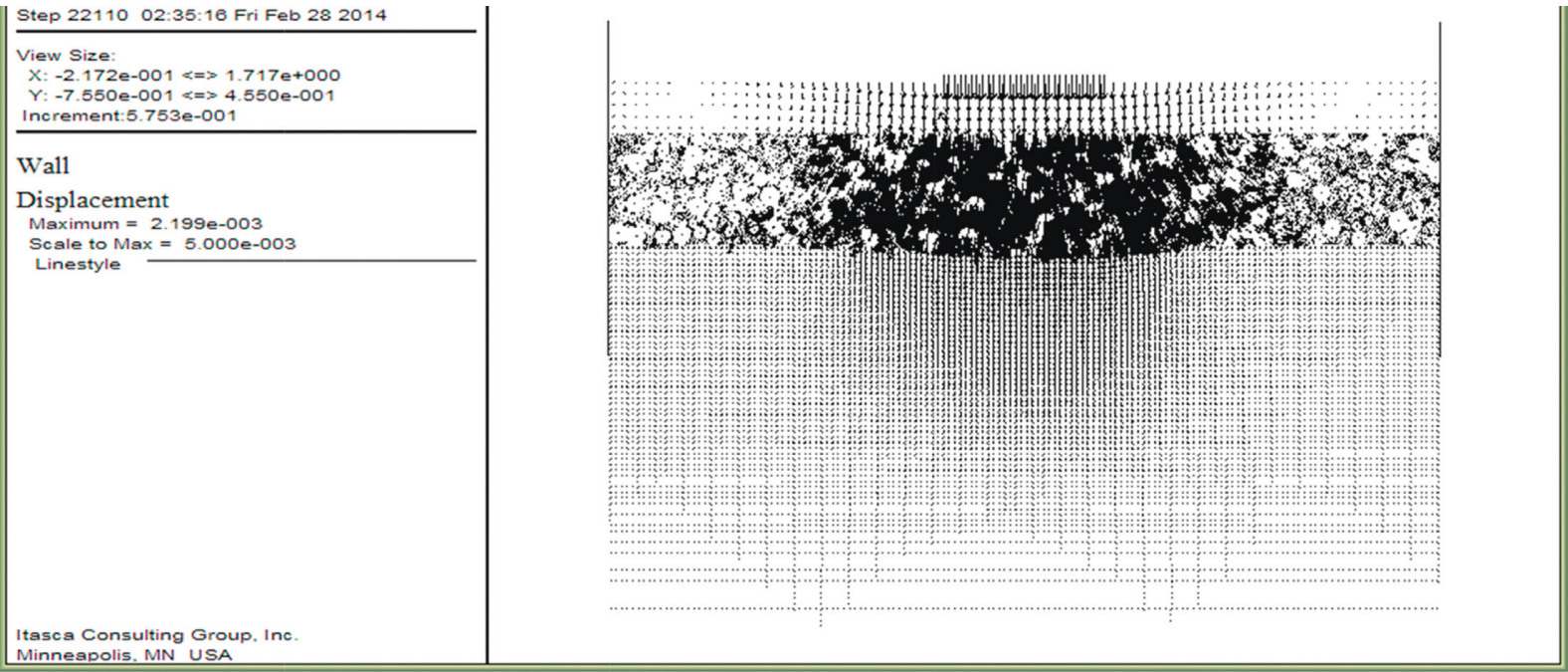

(b)

Figure 7: Particle displacement vector for each layer.

(2) Graded aggregate base layer: graded aggregate is unbound particles, and the assembly of balls is arranged randomly with given size distribution and within the specified region. (3) Subgrade soil layer: this layer is regarded as elastic property and ignored the plastic deformation. Consequently, the generation of balls is the same as the asphalt layer but has relatively small size. (4) Loading plate: a clump, assembly of balls arranged regularly and tightly, is used to apply traffic loading.

After the particle assembly is generated and compacted, boundary and initial conditions are applied to achieve the desired initial equilibrium state.

\section{Results and Discussion}

3.1. Stress Distribution Characteristics. $50 \mathrm{kN}$ force was uniformly distributed on loading plate to simulate action of a wheel. As illustrated in Figure 3, it can be observed that generally the stress of the model is in a symmetrical distribution.
For the stress distribution in the asphalt layer, Figure 4 highlights that compressive stress concentrated area located in on both sides of wheel, while tensile stress concentrated area located in lower part of the asphalt layer. Meanwhile, under the traffic loading, the asphalt layer beneath the wheel suffers from shear and tensile action in the converging zone of compressive and tensile stress. After long-term repeated loading, fatigue cracking and rutting will arise owing to the fatigue failure of the asphalt layer and different vertical strains of two sides.

For the graded aggregate base layer, the stress distribution located mainly in a range beneath traffic loading, which has a double width of wheel approximately and has a trend to expand gradually with increasing depth within the graded aggregate base layer. The traffic load was transferred downward by the graded aggregate base layer and to both sides at the same time (as shown in Figure 5). Consequently, stress in the subgrade soil layer reduced greatly, and correspondingly, deformation is relatively small. 


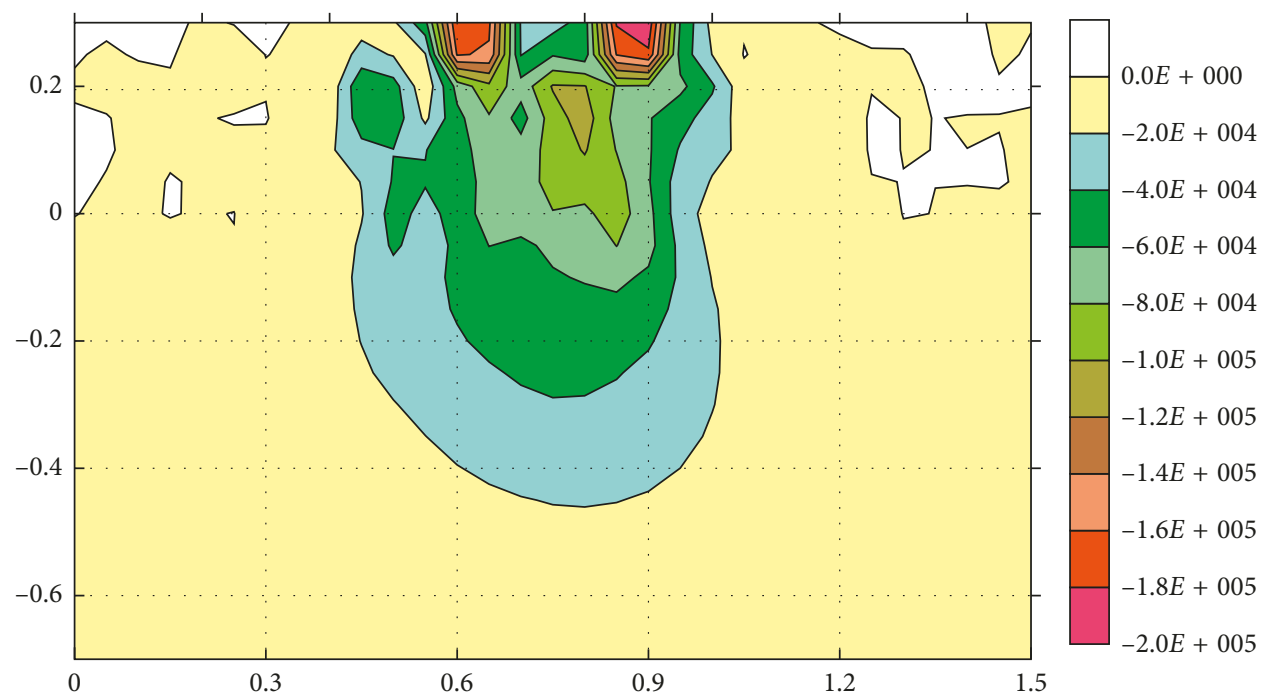

FIgURE 8: Stress contour of the model.
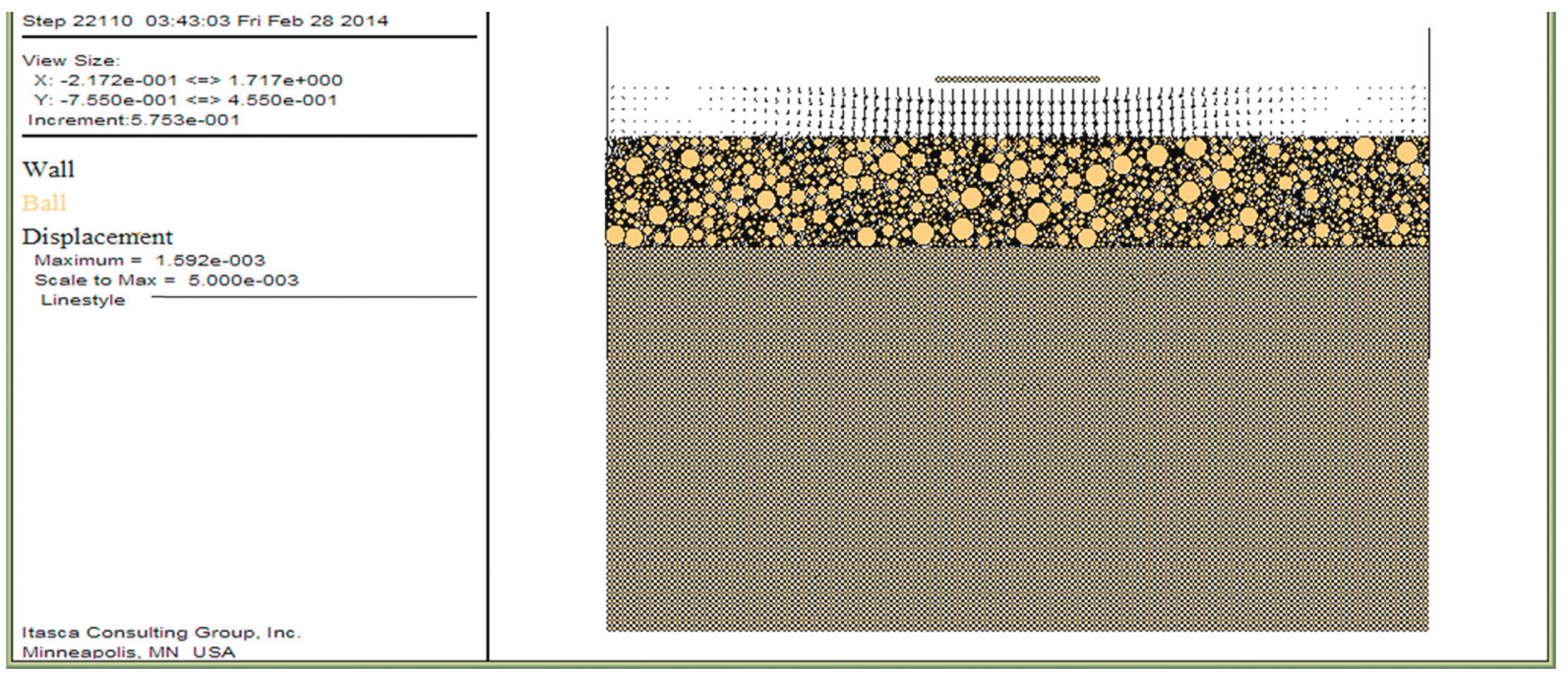

FIGURE 9: Deformation characteristics of the asphalt layer.

For the subgrade soil layer, the stress was distributed well in the subgrade soil layer with a great action scope (as illustrated in Figure 6). And the maximum force between balls was $1.97 \mathrm{kN}$ and, as expected, the maximum stress distribution was right below traffic loading. But due to the appearance of graded aggregate base, the effect of stress dispersion diminished stress value in the subgrade soil layer.

In order to describe stress state visually, stress contour is presented in Figure 7 via a self-made program, which offers a trend of stress quantitatively. It is noted that only presentation of stress value was available. So, for this reason, the failure mode for a specific zone cannot be determined from it. As shown in Figure 8, stress concentration exhibited on the edge of wheel; the maximum stress $200 \mathrm{kPa}$ was slightly greater than mean stress $167 \mathrm{kPa}$, under the traffic loading. Thus, accompanying irregular settlement, it will contribute fatigue cracking and rutting, and finally conform to the actual phenomenon for pavement. Additionally, stress value decreased obviously in the subgrade soil layer because of the stress dispersion of graded aggregate base.

3.2. Displacement Characteristics. Figure 7 illustrates the particle displacement vector for each layer. For the asphalt layer, vertical displacement was the main displacement of the asphalt layer (as shown in Figure 9), with the maximum vertical displacement equal to $2.199 \mathrm{~mm}$, located right below traffic loading. On the both sides of traffic loading, displacement was downward and inclined slightly to the central of loading.

For the graded aggregate base layer, vertical and horizontal deformations included both in graded aggregate base layers (as shown in Figure 10). Displacement concentrated in a finite region right below the loading with a maximum value of $2.159 \mathrm{~mm}$ and extended to both sides gradually with increasing depth. And because of unboned granular material of graded aggregate base, the displacement vector corresponds to stress distribution trends. 


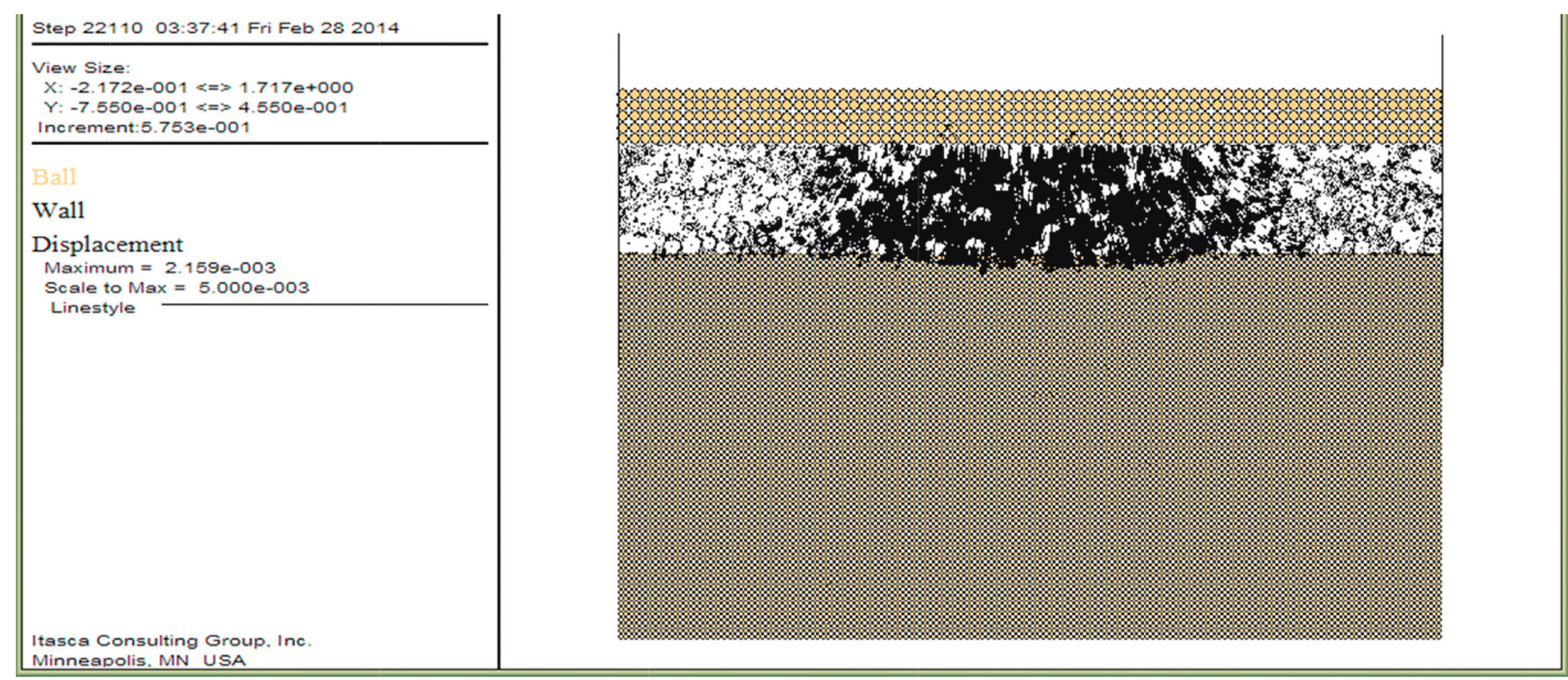

FIGURE 10: Deformation characteristics of the graded aggregate base layer.
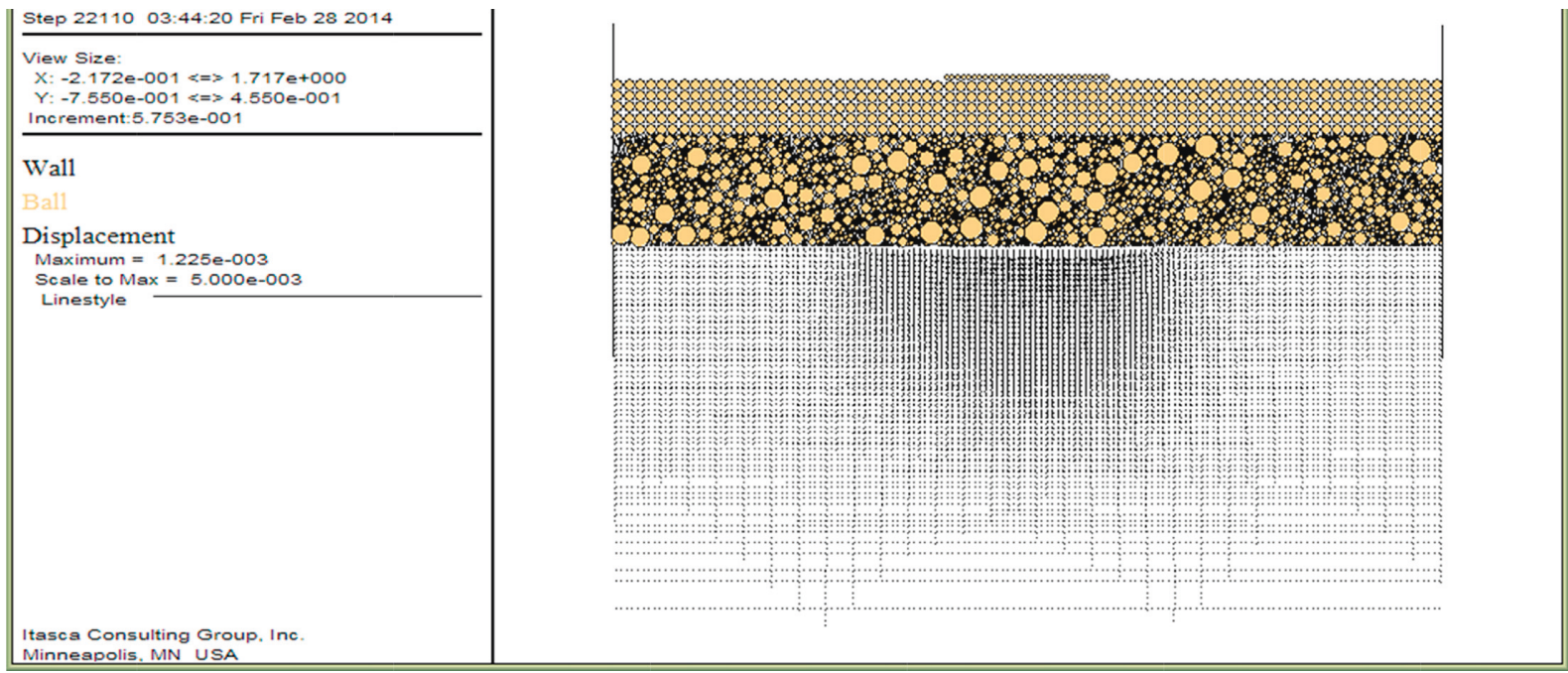

FIgURE 11: Deformation characteristics of the subgrade soil layer.

For the subgrade soil layer, vertical displacement is dominated in the subgrade soil layer with a maximum value of $1.225 \mathrm{~mm}$ located right below the traffic loading, and displacement has a trend to diffuse into both sides (as shown in Figure 11), which corresponds to stress dispersion. Figure 12 provides a visible vertical displacement contour via the selfmade program. Although discontinuity appears in this contour owing to the fact that it comes from DEM which is not a continuum problem, it does not affect the estimation of vertical displacement quantitatively for different regions. For the asphalt layer, the maximum vertical displacement varies between 2.0 and $2.25 \mathrm{~mm}$; consequently vertical deformation is dominated in the asphalt layer as compared to the maximum displacement $2.199 \mathrm{~mm}$ (Figure 10). But for the graded aggregate base layer, the maximum vertical displacement varies between 1.25 and $1.5 \mathrm{~mm}$, which is different significantly from the maximum displacement $2.159 \mathrm{~mm}$ (Figure 11); thus, horizontal displacement cannot be ignored in the graded aggregate base layer. Deformation of the subgrade soil layer was dominated by vertical displacement as the maximum vertical displacement varies between 1.0 and $1.25 \mathrm{~mm}$ (Figure 12), which is close to the maximum displacement $1.225 \mathrm{~mm}$ (Figure 12), and the displacement was relatively small because of the stress dispersion of graded aggregate base.

\section{Conclusions}

A PFC numerical simulation study was conducted to determine stress distribution and deformation behavior of asphalt pavement with graded aggregate base under standard traffic loading.

(1) Stress distribution characteristics demonstrated that compressive stress concentrated area located in on both sides of wheel, while tensile stress concentrated area located in lower part of the asphalt layer; consequently, fatigue cracking and rutting will arise with 


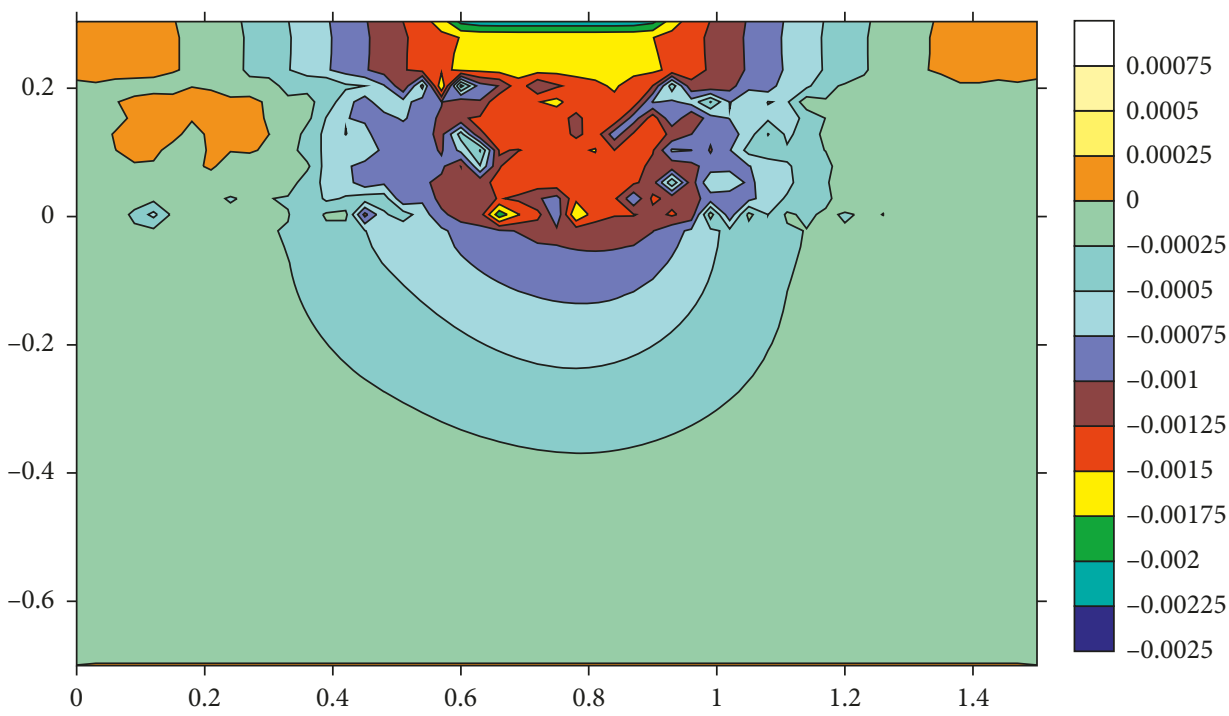

FIgURE 12: Vertical displacement contour of the model.

the fatigue failure of the asphalt layer after long-term repeated loading. The traffic load transferred downward by graded aggregate base and transferred to both sides at the same time and has a trend to expand gradually with increasing depth within the graded aggregate base layer. Therefore, stress was distributed well in the subgrade soil layer with a great action scope, and the value decreased obviously in the subgrade soil layer because of the stress dispersion of graded aggregate base.

(2) Displacement characteristics and the corresponding vertical displacement contour demonstrated that vertical displacement was the main displacement of the asphalt layer, and on the both sides of traffic loading, displacements were downward and inclined slightly to the central of loading. Vertical and horizontal deformations included in both graded aggregate base layers, and displacement extended to both sides gradually with increasing depth corresponding to stress-distribution trends. Vertical displacement was dominated in the subgrade soil layer which was relatively small.

\section{Conflicts of Interest}

The authors declare that they have no conflicts of interest.

\section{References}

[1] M. Ameri, A. Mansourian, M. Heidary Khavas, M. R. M. Aliha, and M. R. Ayatollahi, "Cracked asphalt pavement under traffic loading-a 3D finite element analysis," Engineering Fracture Mechanics, vol. 78, no. 8, pp. 1817-1826, 2011.

[2] A. Setyawan, S. E. Zoorob, and K. E. Hasan, "Investigating and comparing traffic induced and restrained temperature stresses in a conventional rigid pavement and semi-rigid layers," Procedia Engineering, vol. 54, pp. 875-884, 2013.

[3] H. C. Dan, L. H. He, and B. Xu, "Experimental investigation on non-darcian flow in unbound graded aggregate material of highway pavement," Transport in Porous Media, vol. 112, no. 1, pp. 189-206, 2016.

[4] S. H. Kim, J. Yang, and J. Kwon, "Effects of using screening materials in the graded aggregate base layer of flexible pavements," International Journal of Pavement Engineering, vol. 18, no. 2, pp. 97-107, 2017.

[5] K. L. Smith and A. R. Romine, Materials and Procedure for Sealing and Filling Cracks in Asphalt-Surfaced Pavements: Manual of Practice, Publication no. FHWA-RD-99-147, Federal Highway Administration, Washington, DC, USA, 1999.

[6] R. Vidal, E. Moliner, G. Martínez, and M. C. Rubio, "Life cycle assessment of hot mix asphalt and zeolite-based warm mix asphalt with reclaimed asphalt pavement," Resources, Conservation and Recycling, vol. 74, pp. 101-114, 2013.

[7] J. Chen, H. Wang, M. Li, and L. Li, "Evaluation of pavement responses and performance with thermal modified asphalt mixture," Materials \& Design, vol. 111, pp. 88-97, 2016.

[8] H. Wu, B. Huang, and X. Shu, "Characterizing fatigue behavior of asphalt mixtures utilizing loaded wheel tester," Journal of Materials in Civil Engineering, vol. 26, no. 1, pp. 152-159, 2014.

[9] P. Abhijit and P. Jalindar, "Effects of bad drainage on roads," Civil and Environmental Research, vol. 1, no. 1, pp. 1-8, 2011.

[10] S. Werkmeister, A. R. Dawson, and F. Wellner, "Permanent deformation behaviour of granular materials," Road Materials and Pavement Design, vol. 6, no. 1, pp. 31-51, 2005.

[11] M. S. Rahman and S. Erlingsson, "Predicting permanent deformation behaviour of unbound granular materials," International Journal of Pavement Engineering, vol. 16, no. 7, pp. 587-601, 2015.

[12] A. W. Ahmed and S. Erlingsson, "Evaluation of permanent deformation models for unbound granular materials using accelerated pavement tests," Road Materials and Pavement Design, vol. 14, no. 1, pp. 178-195, 2013.

[13] H. Lin, H. Wang, X. Fan, P. Cao, and K. Zhou, "Particle size distribution effects on deformation properties of graded aggregate base under cyclic loading," European Journal of Environmental and Civil Engineering, pp. 1-18, 2017.

[14] M. Ba, K. Nokkaew, M. Fall, and J. M. Tinjum, "Effect of matric suction on resilient modulus of compacted aggregate 
base courses," Geotechnical and Geological Engineering, vol. 31, no. 5, pp. 1497-1510, 2013.

[15] S. K. Yamsani, S. Sekharan, and R. R. Rakesh, "Combined shear and seepage characteristics for selecting drainage layer in near surface hazardous waste disposal facility," Geotechnical and Geological Engineering, vol. 35, no. 2, pp. 871-878, 2017.

[16] T. Saevarsdottir and S. Erlingsson, "Modelling of responses and rutting profile of a flexible pavement structure in a heavy vehicle simulator test," Road Materials and Pavement Design, vol. 16, no. 1, pp. 1-18, 2015.

[17] P. Ullidtz, J. T. Harvey, B. W. Tsai, and C. L. Monismith, Calibration of Incremental-Recursive Flexible Damage Models in CalME Using HVS Experiments, Institute of Transportation Studies, University of California, Berkeley, CA, USA, 2006.

[18] Y. Zhao, C. Zhou, W. Zeng, and Y. Ni, "Accurate determination of near-surface responses of asphalt pavements," Road Materials and Pavement Design, vol. 16, no. 1, pp. 186-199, 2015.

[19] T. D. White, J. E. Haddock, A. Hand, and H. Fang, Contributions of Pavement Structural Layers to Rutting of Hot Mix Asphalt Pavements, National Academy Press, Washington, DC, USA, 2002.

[20] E. Coleri, J. T. Harvey, K. Yang, and J. M. Boone, "A micromechanical approach to investigate asphalt concrete rutting mechanisms," Construction and Building Materials, vol. 30, pp. 36-49, 2012.

[21] J. A. Fleischmann, M. E. Plesha, and W. J. Drugan, "Determination of yield surfaces for isotropic non-cohesive particulate materials by the discrete element method," Geotechnical and Geological Engineering, vol. 32, no. 4, pp. 1081-1100, 2014.

[22] P. Roul, A. Schinner, and K. Kassner, "Discrete-element computation of averaged tensorial fields in sand piles consisting of polygonal particles," Geotechnical and Geological Engineering, vol. 29, no. 4, pp. 597-610, 2011.

[23] D. Yang, Y. Xia, D. Wu, P. Chen, G. Zeng, and X. Zhao, "Numerical investigation of pipeline transport characteristics of slurry shield under gravel stratum," Tunnelling and Underground Space Technology, vol. 71, pp. 223-230, 2018.

[24] R.-H. Cao and H. Lin, "Experimental and numerical study of failure behavior and energy mechanics of rock-like materials containing multiple joints," Advances in Materials Science and Engineering, vol. 2017, Article ID 6460150, 17 pages, 2017.

[25] M. Bahaaddini, G. Sharrock, and B. K. Hebblewhite, "Numerical investigation of the effect of joint geometrical parameters on the mechanical properties of a non-persistent jointed rock mass under uniaxial compression," Computers and Geotechnics, vol. 49, pp. 206-225, 2013.

[26] J. W. Park and J. J. Song, "Numerical simulation of a direct shear test on a rock joint using a bonded-particle model," International Journal of Rock Mechanics and Mining Sciences, vol. 46, no. 8, pp. 1315-1328, 2009.

[27] X. Ding, L. Zhang, H. Zhu, and Q. Zhang, "Effect of model scale and particle size distribution on PFC3D simulation results," Rock Mechanics \& Rock Engineering, vol. 47, no. 6, pp. 2139-2156, 2014.

[28] G. R. McDowell and M. Lu, "Discrete element modelling of railway ballast under monotonic and cyclic triaxial loading," Géotechnique, vol. 60, no. 6, pp. 459-467, 2010.

[29] Z. Cheng, H. Rui, and Z. Jian, "Particle contact characteristics of coarse-grained soils under normal contact," European Journal of Environmental and Civil Engineering, pp. 1-16, 2017.

[30] S. Wang, R. Huang, P. Ni, R. P. Gamage, and M. Zhang, "Fracture behavior of intact rock using acoustic emission: experimental observation and realistic modeling," Geotechnical Testing Journal, vol. 36, no. 6, p. 20120086, 2013.

[31] CCCC Highway Consultants Co., Ltd., Specification for Design of Highway Asphalt Pavement, China Communications Press, Beijing, China, 2006. 


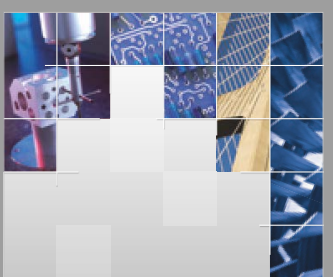

\section{Enfincering}
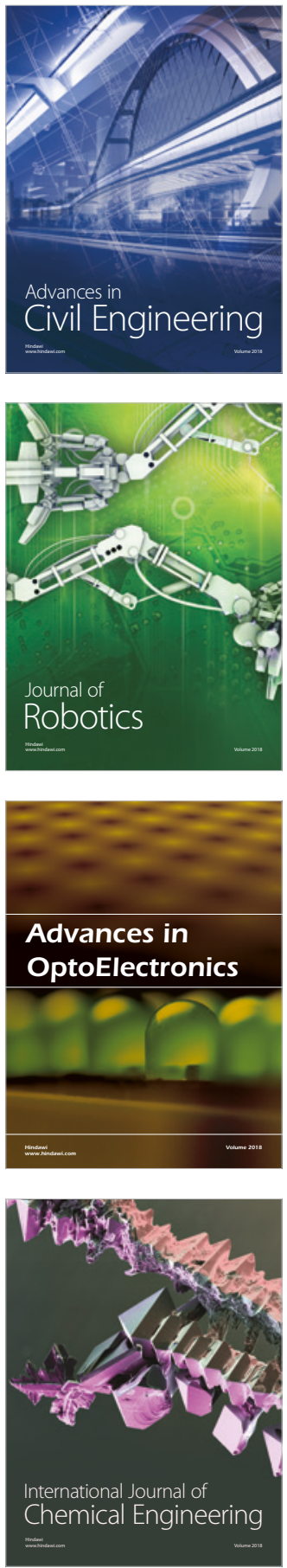

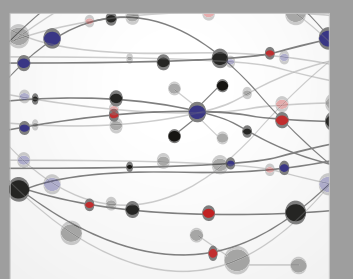

\section{Rotating \\ Machinery}

The Scientific World Journal

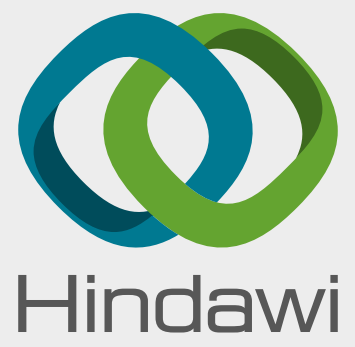

Submit your manuscripts at

www.hindawi.com
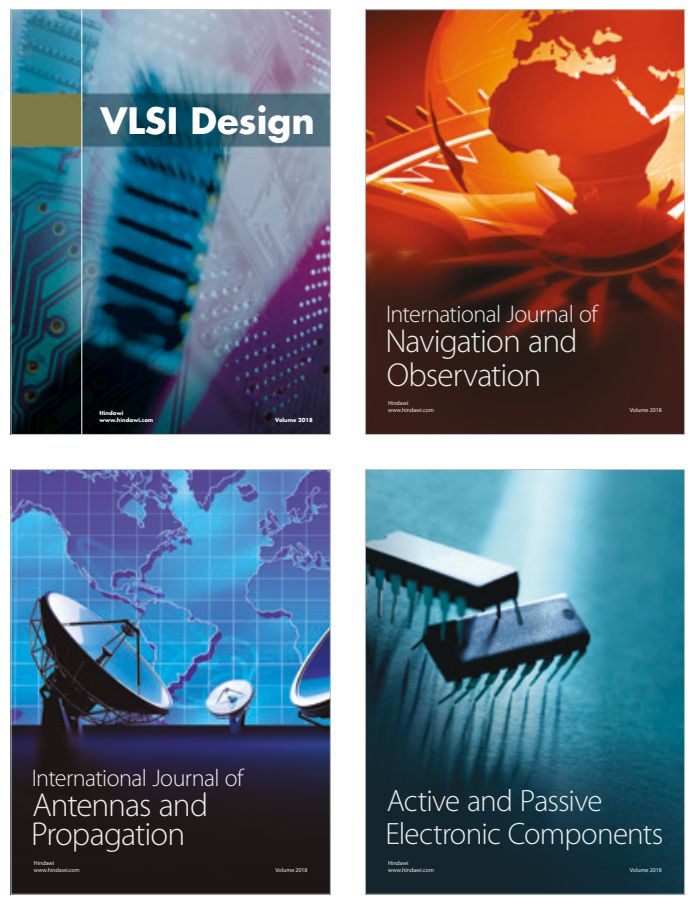
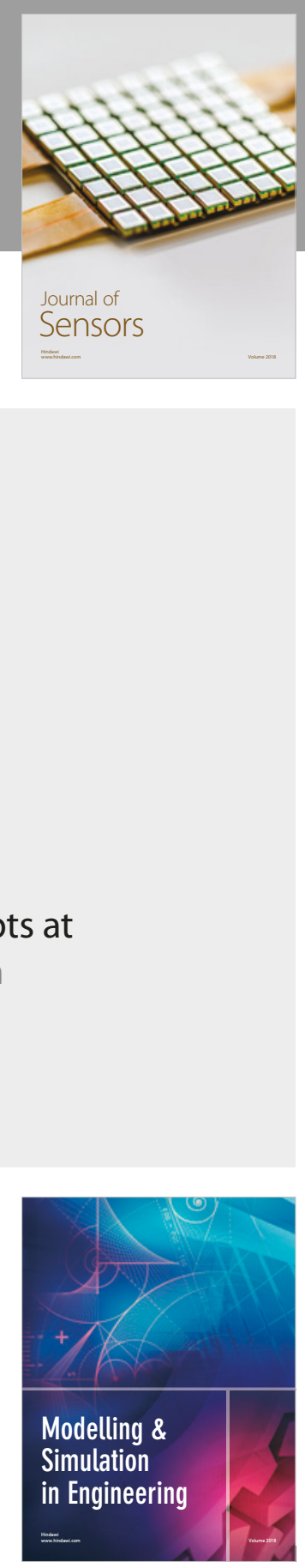

\section{Advances \\ Multimedia}
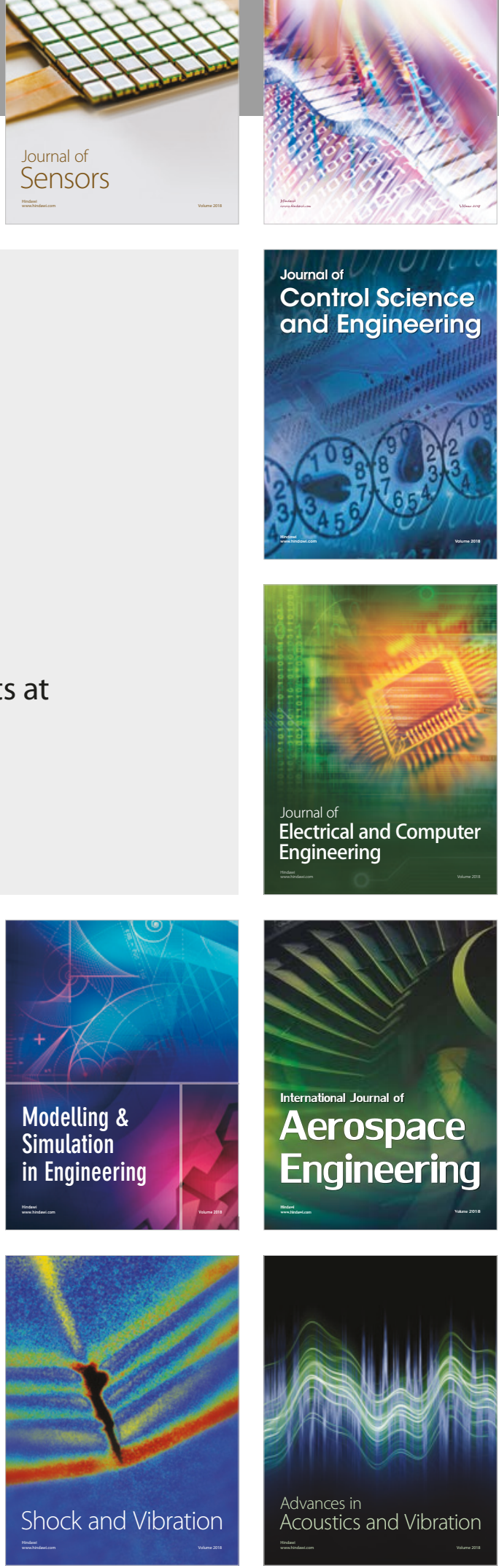